\title{
El Arte, un espectador de la Guerra. Del dolor de los cuerpos femeninos a la profanación del Ser
}

Alejandra Solórzano

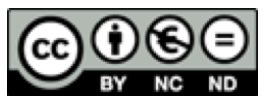

Esta obra está bajo una licencia Creative Commons

Reconocimiento-No comercial-Sin Obra Derivada 



\title{
El Arte, un espectador de la Guerra. Del dolor de los cuerpos femeninos a la profanación del Ser.
}

\author{
Alejandra Solórzano \\ Universidad de Costa Rica \\ ciudadmigrante@gmail.com
}

Recibido: 16 de enero del 2016 Aprobado:18 de febrero de 2016

\begin{abstract}
Resumen
El arte en algunas de sus obras más importantes, ha sido observador declarante de la historia y la continuidad de un cierto proceso de "naturalización" por la que el cuerpo femenino ha sido botín de guerra. Las autorías que ilustran a través del tiempo "el rapto", y en alguna medida la justificación de robo, sometimiento y sacrificio de mujeres a causa de su belleza como recompensa de guerra, revelan un problema vigente y crítico sobre nuestra contemporaneidad, el secuestro del cuerpo por sobre la anulación del ser femenino. Importantes obras de arte que registran de forma bella y acrítica, sucesos de la mitología tales como el rapto de Europa, el secuestro de Perséfone, las Sabinas, el sacrificio de Ifigenia, por mencionar algunas, fundamentan las bases de una maquillada "justificación" de la violencia sexual y la esclavitud femenina, que en la historia del mundo, casos como el de Boc Dong Kim y las "mujeres de solaz" o "mujeres de confort" de Corea, China, Filipinas, Malayas, entre otras (Segunda Guerra Mundial), y el caso de las mujeres de Sepur Zarco en Guatemala (1980-1983), son ejemplos de un doble crimen de guerra. Se anula al Sujeto femenino por la instrumentalización de su corporalidad.

La belleza como mandato social y asignación de género es un enemigo profanador de la constitución ontológica del ser femenino. La mujer como cuerpo y el cuerpo que le es despojado. En tanto, el arte ha sido un testigo pasivo y quizá, en su indolencia, legitimador.
\end{abstract}

Palabras clave: dolor, cuerpos femeninos, guerra, Sujeto, ontología, arte, ser femenino.

\begin{abstract}
In some of its most important works, Art has been an outspoken observer of history and of the continuity of a certain process of "naturalization" by which the female body has become spoils of war. The
\end{abstract}




\section{Artículos}

artists that throughout history illustrate the "rapture," and, to some extent, the justification of the theft, subjugation, and sacrifice of women as spoils of war because of their beauty, reveal a prevailing and critical problem of our times: the kidnapping of the body through the abolition of the female Self. Important works of art register, both beautifully and uncritically, mythological events such as the abduction of Europe, the kidnapping of Persephone, the rape of the Sabine women, the sacrifice of Iphigenia, to mention a few examples. Thus, they become the foundation of an embellished "justification" of sexual violence and female slavery -as in world history cases like Bok-dong Kim and the comfort women in Korea during World War II, or that of Guatemala's Sepur Zarco women (1980-1983) - which are examples of a double war crime. The female Self if obliterated through the instrumentalization of her cor-

porality. Beauty as socially-demanded and gender-assigned is a defiling enemy of the ontological act of being female, and it creates the image of woman as body and as the body that is taken away. Meanwhile, art has been a passive and, in its indolence, maybe even a legitimizing witness of this process.

Key words: pain, female bodies, war, Subject, ontology, art, be feminine. 
Vedme aquí, dioses ¿He de caer más bajo? Aquí es todavía la tierra. Y ese rayo de luz que se desliza como una sierpe, esa luz que me busca será mi tortura mayor. No poder aquí ni aún librarme de ti, luz de Sol. Sol de la Tierra. (M. Zambrano, 2012, p. 177)

Acaso porque aquello primero sobre todo cuerpo, sobre toda materia, es la luz, la Antígona de Zambrano, en su monólogo declara la Luz como dolor de la Verdad sobre los cuerpos. Luz sobre su cuerpo que es conciencia nacida de la necesidad de desenterrar aquello que ha sido condenado a no ser. Pienso entonces en esa luz sobre los Cuerpos. Pienso luego en ese dolor de los Cuerpos, en el dolor y la historia que tomó residencia en los cuerpos femeninos, que a través del arte, deja una huella sutil del lugar y el estatus que asigna a los cuerpos de las mujeres en el arte.

La ruina de la guerra fijó su blanco en ellos, en los cuerpos de las mujeres. Diosas de la mitología griega, mujeres de noble estirpe, eternas y mortales comparten, en su mayoría una misma condición: ser dueñas del dolor. El patrón de la guerra ha sido condenar a las mujeres a una sutil condición ontológica de cuerpo como botín, sinónimo de belleza para el confort, la satisfacción del deseo y la ocupación masculina. De esta forma, el ser femeni$n o$ es anegado en la belleza, en el objeto para saciar confort y placer que disuelve al Sujeto, y lo condena a un emparedamiento recubierto con el tapiz de la técnica y la belleza.

Simone Weil, en su ensayo sobre la guerra, "La Ilíada o el poema de la fuerza", publicado en 1940, señala que la violencia convierte en cosa a quien está sujeto a ella. Más allá de lo que propone Weil, podríamos pensar que también lo exalta "intencionalmente" para convertirlo en mártir o en héroe, justificando con ello, en el caso de las figuras femeninas de la historia y la mitología, una perpetuación de la asignada condición sacrificial para satisfacción de los hombres, tal como la épica griega narra, pero también, como "naturalización" de la violencia "justificada" en la belleza femenina que motiva el rapto de sus cuerpos. Lo anterior nos conduce inevitablemente al precipicio donde el ser femenino como sujeto es anulado y su valía, su telos, no es más que el de ser un instrumento para saciar el desahogo el deseo masculino. Con este panorama, nada más allá de eso importará para los juegos de la guerra y para el arte. En el arte, la imagen muestra el rapto, pero no lo cuestiona sino que lo embellece.

\section{Figura 1}

El rapto de Europa. Francisco José de Goya y Lucientes (1772)

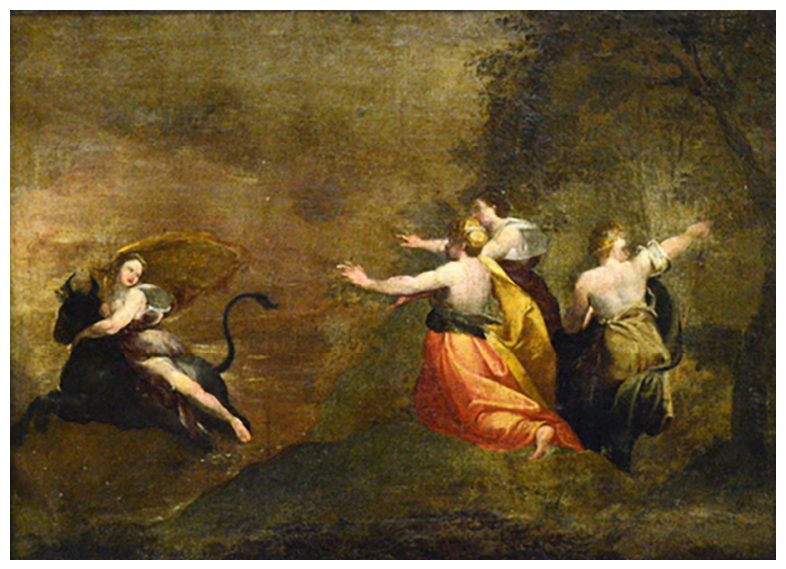

Fuente: Wikimedia Commons (2016) 


\section{Artículos}

"La estética vende, pero la ética derrocha", señala Camnitzer. Sobre esa premisa a la ética en el arte importaría la última mirada de Europa cuando vuelve su rostro hacia el río de donde Zeus abruptamente la secuestró. Las interpretaciones de esta obra, el "Rapto de Europa", por Rembrandt (1631), principalmente en Tiziano (1560-1562), la copia de Rubens (1628-1629) e incluso más contemporáneamente, la escultura de Botero, enfocan la belleza de la obra en la voluptuosidad del cuerpo de Europa, no en el espanto, no el dolor que produce su secuestro; entonces, ¿qué simbolizaría ello?

Para saberlo, hay que tomar posición. Para esto, es necesario primero comprender que el símbolo, en este caso la obra de arte -la obra como símbolo- es la cristalización de una realidad mundana de la interioridad de un sujeto que se expresa en ella. Detrás de la obra hay un autor, individuo que expresa su intención como Sujeto. La obra de arte es, en este caso, un símbolo; es decir, la reunión de dos partes o mitades que, en conjunto, forman el sentido de una realidad del ser, que es idealizada y que, a su vez, está cargada de valores emocionales. La obra de arte, por tanto, atestigua sucesos históricos, los registra como vehículos de pensamiento y los simboliza; es decir, los carga de sentido, los idealiza.

En segundo lugar, es necesario pensar en el saber simbolizado que habla sobre los cuerpos femeninos. No en vano D. Huberman advierte: para saber hay que tomar posición. ${ }^{1}$ Pero ¿a qué saber se refiere con esto? Sobre lo que se afronta (la obra de arte) y de lo que nos apartamos (las intenciones) ¿La historia? ¿Los fragmentos de la historia? Para saber hay que tomar posición. Se piensa nuevamente en los cuerpos femeninos, en la condición de ser mujer en el contexto de las guerras y en obras de arte que han registrado fragmentos de historia, de hazañas épicas y mitológicas en torno a las guerras.

\section{Figura 2}

El Sacrificio de Ifigenia. Mosaico encontrado en 1849.

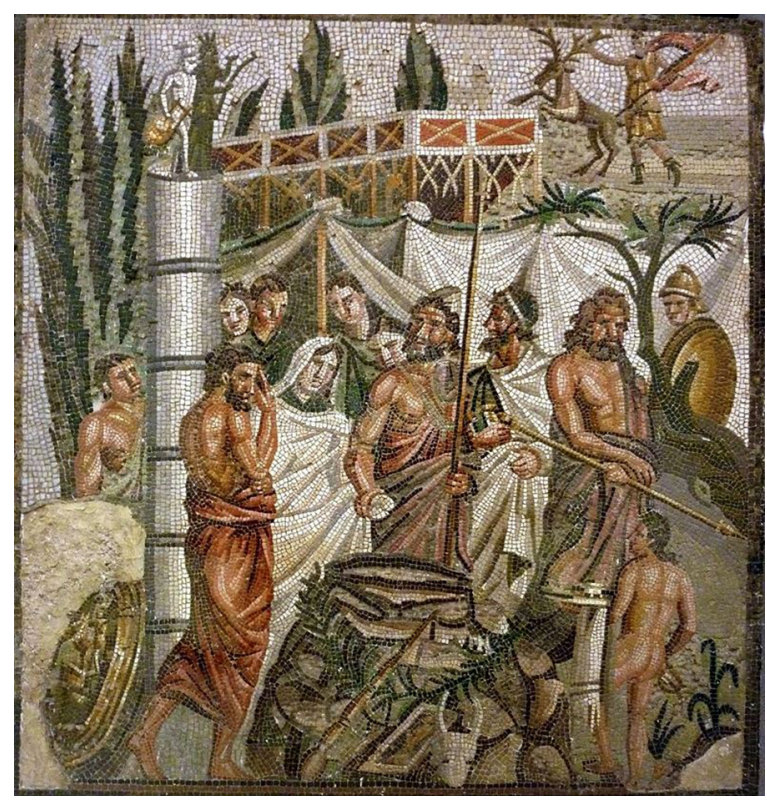

Fuente: Museo Arqueológico de Catalunya, España.

${ }^{1}$ Didi-Huberman, G. (2008). Cuando las imágenes toman posición. El ojo de la historia. España: Editorial Antonio Machado, p.11. 
Europa no es la única raptada por una figura masculina de poder. Le acompaña un linaje de personajes femeninos que también han sido secuestradas y sometidas involuntariamente para ser consortes de sus raptores. Por mencionar tan solo algunas: Perséfone (o Proserpina), Las Sabinas, Helena de Troya, y de modo diferente pero igualmente trágico, es el sacrificio de Ifigenia a manos de su padre Agamenón, quien lanza a su propia hija al mar, en ofrenda a Poseidón, para poder llegar a tierra firme con su embarcación y tripulantes hombres.

Estos patrones de sujeción de los cuerpos de las mujeres abarcan una clara construcción ontológica del ser femenino. La figura femenina en el arte es siempre un medio y no un fin. Su rapto, su sacrificio, su constante referencia a la utilización y al castigo la sitúan como objeto y no como ser. Su individuación, su configuración ontológica es la de un cuerpo para el hombre. Un cuerpo, materia para la transacción, la complacencia, el sacrificio, negociación del recurso, objeto entre los hombres.

De tal suerte, la arquitectura ontológica del ser femenino, es en realidad, la metáfora de una identidad femenina "cósica": mujer-objeto, cuerpo-objeto en que la guerra y sus jugadores convierten a las mujeres. Asistimos, somos testigos de un crimen existencial y ontológico, pues de modo que si la obra de arte como símbolo -funda cultura-, entonces el emparedamiento del ser femenino, de mujer como Sujeto, cumple su cometido en el arte.
El cuerpo femenino - no la mujer-, es objeto de deleite para el espectador, es objeto y no Sujeto en la obra de arte, por tanto, objeto de placer, medio y la arena donde tiene lugar la trágica escena de estos crímenes: la historia, la mitología y, por supuesto, el arte que lo atestigua ajeno y acrítico.

\section{Figura 3}

Teseo raptando a Helena. Ánfora ática de figuras rojas. Siglo VI a. C.

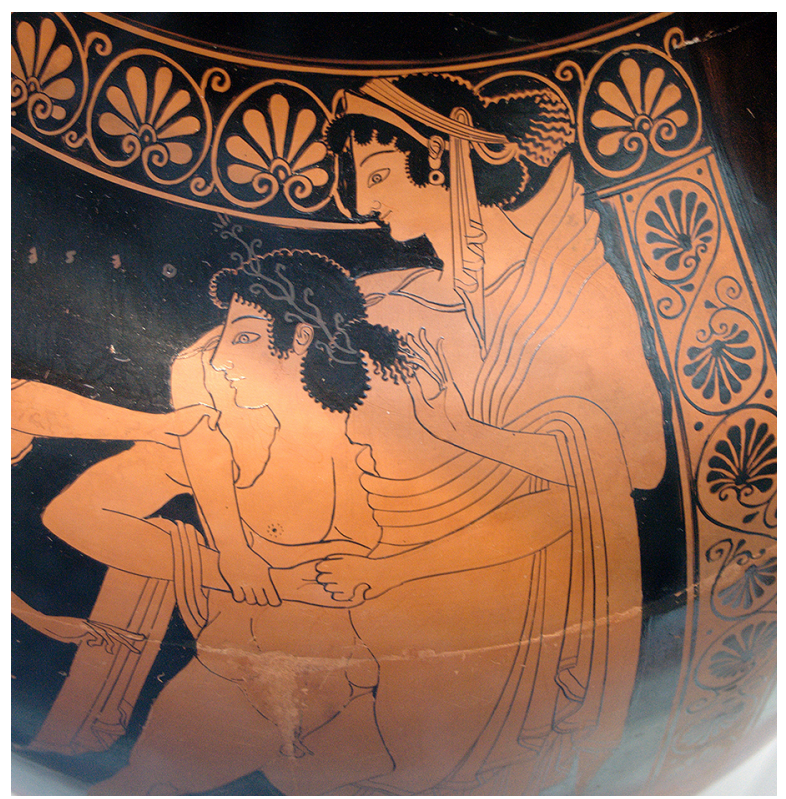

Fuente: Mitología en el arte

Las reiteradas referencias al rapto femenino manifiestan en el arte una intención. Estas no derivan del autor unívocamente, tampoco únicamente de su contexto y circunstancia como sentenciaría Ortega y Gasset, sino que también de una tradición que asume la costumbre como derecho, "naturalización" 


\section{Artículos}

$y$, en consecuencia, dogma del acto como un norma, como patrón. En la guerra hay reglas que deben cumplirse. Una de ellas es que la población civil -mujeres, niños y niñas, ancianos- no debe ser un blanco de guerra, pero Sontag lo resume así: "La guerra es un juego de hombres. La máquina de matar tiene sexo y es masculino" (Sontag, Susan; 2003, p.8).

Pienso... en contextos de guerra diversos y en las obras de arte observo diferentes cuerpos para los mismos fines, secuestrados, torturados, violados, esclavizados, pero todos con un mismo género: femenino.

El carácter connotativo de la obra de arte es susceptible de interpretación. Sin embargo, puede considerarse una interpretación diferente para las mismas referencias simbólicas respecto de una fundación de cultura concreta; como bien apunta Flusser, si las imágenes son mediaciones entre ser humano y mundo, el resultado de esta sucesiva construcción simbólica, la configuración del ser femenino en el arte, no puede sino derivar en una construcción que convierte ciertos hechos históricos (los raptos, el sometimiento involuntario de las mujeres para la instrumentalización de sus cuerpos) en un acto mediante el cual el arte empareda la violación de los cuerpos, asigna a estos un estatus periférico al crimen y sitúa el concepto de belleza y el cuerpo femenino como el eje de los demás elementos que orbitan en torno a ello.
La transubstanciación del rapto en belleza a través de la imagen, de la obra de arte como mediadora entre ser humano y mundo- creadora de significados, de sentido, como fundadora de cultura, teje una relación de intenciones que residen en la obra de arte que justifican, por tanto, el acto, el crimen que se atestigua pasivamente en la obra. No es casual que en las mitologías griega y romana, previamente a la descripción literaria de los raptos, se describe la belleza de Helena, de Perséfone, la justificación del rapto de Las Sabinas, la "necesidad" de sacrificar a Ifigenia para que Agamenón y todos los guerreros de su embarcación vuelvan finalmente a casa.

\section{Figura 4}

El Rapto de Proserpina (1560). Niccolò dell'Abbate. Museo del Louvre

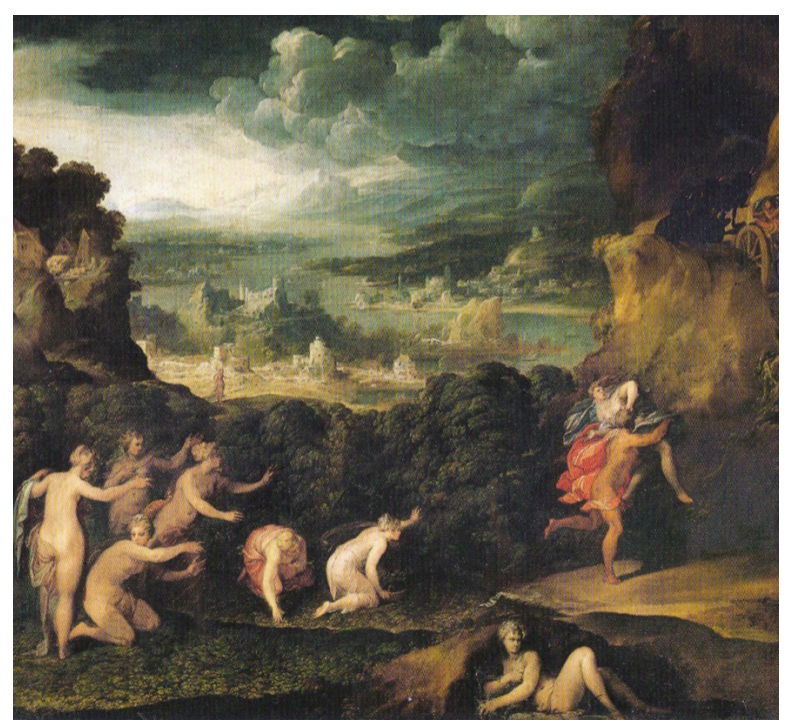

Fuente: Wikimedia Commons 
Figura 5

Mujeres de Sepur Zarco, Guatemala (2015)

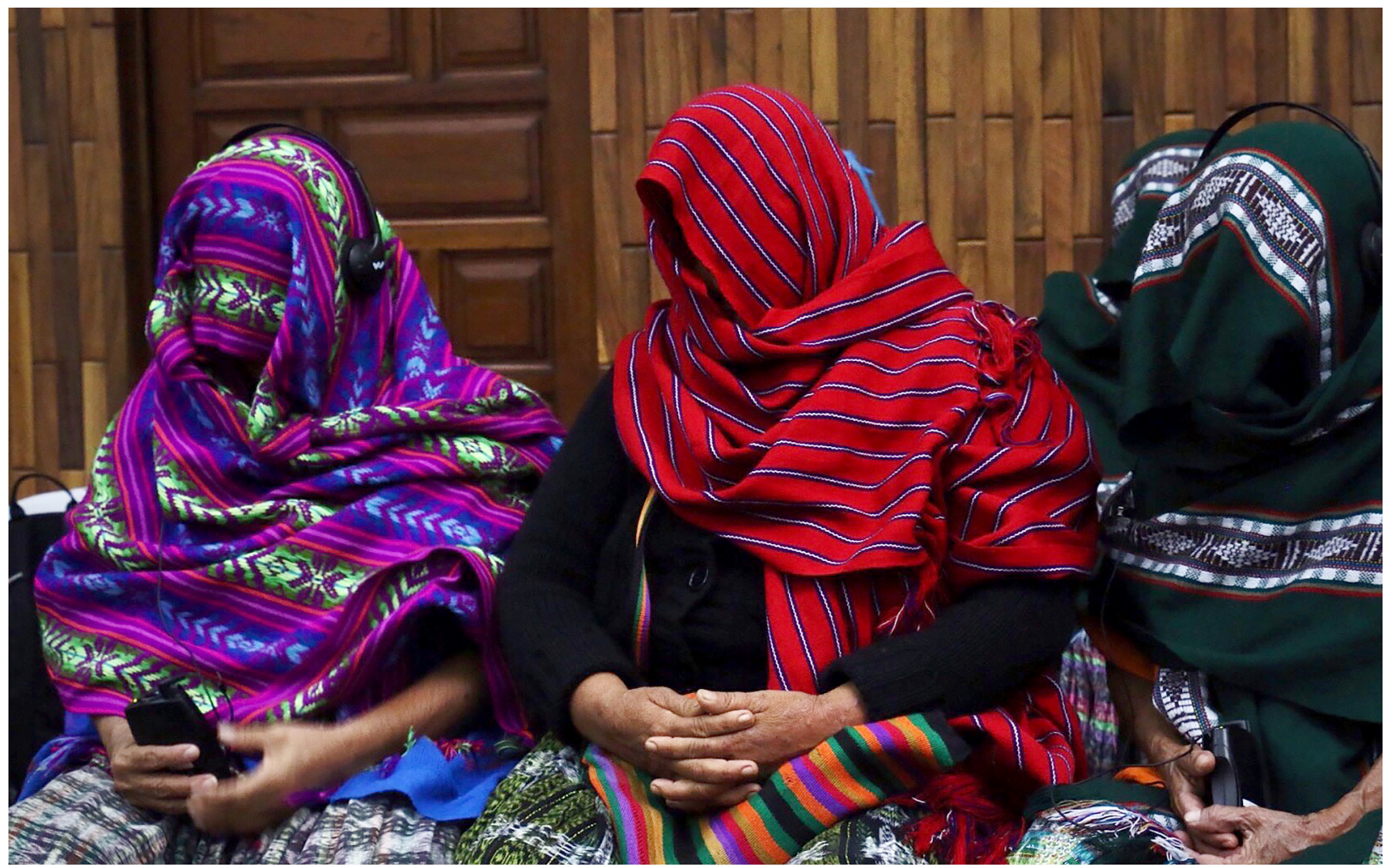

Fotografía por Andrea Carolina Estrada Rodríguez,

Resulta complejo hablar de los límites de la estética y de la ética en la obra de arte.

La manera más resuelta para acercar esta reflexión sobre el cuerpo femenino en el arte, es el presente. D. Huberman señala que este tomar posición es exigir algo; ello implica situarse en el presente para aspirar a un futuro. Todo cuanto sucede, cuanto existe, se asienta sobre el fondo de una temporalidad que nos precede, nos abarca y apela a nuestra memoria colectiva. El punto de partida es, pues, apelar a la memoria y a los intentos de olvido. Yo sumaría a ello una actitud crítica del(a) espectador(a), una mirada que desentrañe las intenciones, la ideología de la micro-política de los cuerpos en el arte; es decir, romper la pared de la belleza y de la técnica para encontrar y hacer que la luz entre y alumbre el dolor y las heridas en los cuerpos femeninos que han sido presos del emparedamiento del arte y de la belleza.

Quería salirme de mi cuerpo 


\section{Artículos}

Antígona: - Y ahora ¿vienes a decirme algo, luz del Sol? Si al fin te oyese, si me dieras esa palabra, una sola, que viniera derecha al fondo de mi corazón, allí, donde ahora lo sé, ninguna palabra, ni la de mi juez, ni la de mi hermana, ni la del amor nunca ha llegado; donde no entró palabra alguna, ni llanto ni gemido, ni voz alguna de criatura viviente: ni el gemido de un toro, ni el canto de la alondra, ni el poderoso arrullo del mar llegó nunca, ni nada de la vida. Tu palabra, luz, sin que yo la entienda, dámela, luz que no me dejas, palabra nacida de ti y no de ese Sol. (M. Zambrano, 2012, p. 177)

El arte ha sido un observador y declarante de la historia y continuidad de este proceso de "naturalización" del cuerpo femenino en botín de guerra. Los autores, las obras que ilustran "el rapto" en sucesivas referencias a lo largo del tiempo, parecen "justificar" en alguna medida el sometimiento y sacrificio de mujeres como recompensa de guerra. Esta reflexión no apela en sí a lo que el arte debe o no ser, sino señalar un problema vigente y crítico sobre nuestra contemporaneidad: la anulación del ser femenino como Sujeto, y la asignación, el mandato de cumplir su estatus instrumental.

Durante la Segunda Guerra Mundial, más de 200 mil mujeres jóvenes y niñas (principalmente surcoreanas, chinas, filipinas, malayas, holandesas, por mencionar algunas) fueron víctimas del secuestro y de tortura y esclavitud sexual por ejércitos contendientes. Seis siglos antes de nuestra era, un jarrón ático de figuras rojas muestra el rapto de
Helena de Troya a manos de Teseo para hacerla su cónyuge. Hoy, después de 2600 años, la guerra ha sofisticado sus mecanismos de sujeción sobre los cuerpos de las mujeres. En épocas anteriores, las violaciones y muertes de mujeres y niños eran definidas como daños colaterales. En la actualidad, la tortura y la esclavitud sexual son una estrategia y un blanco claro y sistematizado de las guerras.

En el 2015, quince mujeres q'eqchi' fueron víctimas de violación sexual, esclavitud doméstica y sexual, en el destacamento militar Sepur Zarco en el Estor, Izabal (Guatemala), entre los años 1982 y 1983 por manos del Ejército de Guatemala. Los acusados, fueron condenados a más de 200 años de cárcel, después de una largo y persistente proceso de lucha y presión social. Después de 33 años, las mujeres de Sepur Zarco rompieron el silencio para reconstruir su dignidad y una nueva mirada de justicia con la cual recuperar sus cuerpos del silencio, recuperarlos de la ocultación, del estigma social que las criminaliza y culpabiliza. Esto último recuerda la intención "naturalizadora" del arte, por el que las mujeres son las supuestas responsables de la agresión sexual a causa de su propia condición femenina.

Las mujeres de Sepur Zarco han instaurado un paradigma, contrario a la analogía en el arte, sobre la ocultación de sus cuerpos. Decidieron tapar sus cuerpos, ocultarlos de la luz y de las miradas durante el proceso de juicio de sus victimarios. Cubrieron sus rostros, su piel de la luz. Tal como Antígona, ellas condenan la luz que alumbra el dolor 
de sus cuerpos; la luz, también en la obra de arte, actúa como un testigo de las secuelas del terror.

Ahora bien, si nos preguntamos ¿por qué se rapta, se viola a las mujeres en las guerras? ¿Por qué el cuerpo femenino es el blanco del dolor y la tortura? ¿Por qué parece ser un tópico en la obra de arte? Algunas de las respuestas que nos acercan a la reflexión sobre la primera cuestión, fue ofrecido por el peritaje del caso de las mujeres de Sepur Zarco, realizado por Aura Cumes. En primer lugar, la sujeción del cuerpo femenino asegura la sumisión de las mujeres mediante el ataque contra su cuerpo; se les recuerda, con ello, que no son dueñas de sus propios cuerpos. En el arte, las mujeres no son Sujetos, son objetos de la mirada masculina, son el botín de la recompensa, de la satisfacción de los jugadores de la contienda. La deshonra y la vergüenza a que son sometidas asegura que el violador obtendrá el silencio de su víctima. En segundo lugar, la violación a las mujeres tiene como objetivo desmoralizar y derrotar al grupo que está siendo sometido. Esto implicaría un desafío a la masculinidad y a la hombría, considerando los cuerpos de las mujeres como territorios que pertenecen a los hombres.

En su artículo, "Las nuevas formas de la guerra y el cuerpo de las mujeres", la antropóloga Rita Laura Segato señala una "pedagogía de la crueldad" en la que niños, niñas y mujeres, son transformados en un objetivo estratégico del paisaje bélico (Segato, 2014, p.1)

En las obras de arte referenciadas y en la historia de las guerras, el cuerpo de las mujeres es reconfigurado ontológicamente como un territorio paralelo a la conquista de los enemigos. Los cuerpos femeninos, de igual forma, son reconceptualizados como espacios sitiados e inseminados por ejércitos de ocupación.

Segato señala la importancia de reconocer que la agresión a los cuerpos frágiles -no cuerpos guerreros- expresan con su sufrimiento el dolor y la amenaza de toda la colectividad (Segato, 2014, p.1). El territorio, en otras palabras, está dado por los cuerpos. De allí que los cuerpos de las mujeres (diosas y mortales) sean los protagonistas de las obras de arte que reflejan las victorias y derrotas entre ejércitos mediante su dominación, dolor y ocupación. Más trágico y truculento en la historia del arte, resulta la belleza con que son expuestas las escenas de rapto, sacrificio o sometimiento de las mujeres en procura de la posesión de sus cuerpos.

Las imágenes, la pintura y el arte habita entre el mundo de los signos y el mundo de la corporalidad, advierte D. Huberman, del mismo modo en que he citado, emanan signos y corporalidad. La impotencia frente a la crueldad en que tal brutalidad es extraída y presentada a nuestros ojos con belleza, nos habla de una cierta indolencia y legitimación de que anula cualquier intención crítica mínima contra el hecho. Las mujeres de Sepur Zarco descubrieron sus rostros después de que se dictó la condena y el castigo a sus victimarios. La luz alumbra por primera vez sus cuerpos en proceso de sanación por 


\section{Artículos}

la justicia. La luz irradia en los rostros y los cuerpos femeninos que han sido dignificados, reivindicados. En los 33 años de impunidad, sus cuerpos fueron objetos de dominación ante la carencia de justicia.

Cuando estas mujeres rompen el paradigma de la dominación, cuando consiguen la justicia y trascienden su no ser oculto en el silencio emparedado en la impunidad, para convertirse en Sujetos, en Sujetos políticos de la autogestión de su ser femenino, de su estatus de dignidad, es que deciden romper su ocultación. Ahor, la luz es digna de alumbrar su historia, de alumbrar el dolor y la reivindicación de sus cuerpos. De tal forma que, aún contra esta impotencia ante la belleza con que en el arte sitúa la dominación de los cuerpos femeninos, y la sobrecogedora memoria histórica de las Mujeres de Sepur Zarco que rompieron el emparedamiento de la impunidad, dejo las palabras de Bertolt Brecht, sobre la ensayada "naturalización" de la violencia y la dominación de los cuerpos de las mujeres en el arte, en la historia, en la actualidad: "Que en esta época de confusión sangrienta, de desorden instituido, de arbitrario planificado, de humanidad deshumanizada, nada se pretenda natural, a fin de que nada se diga inmutable".
Figura 6

Mujer de Sepur Zarco, Guatemala (2015)

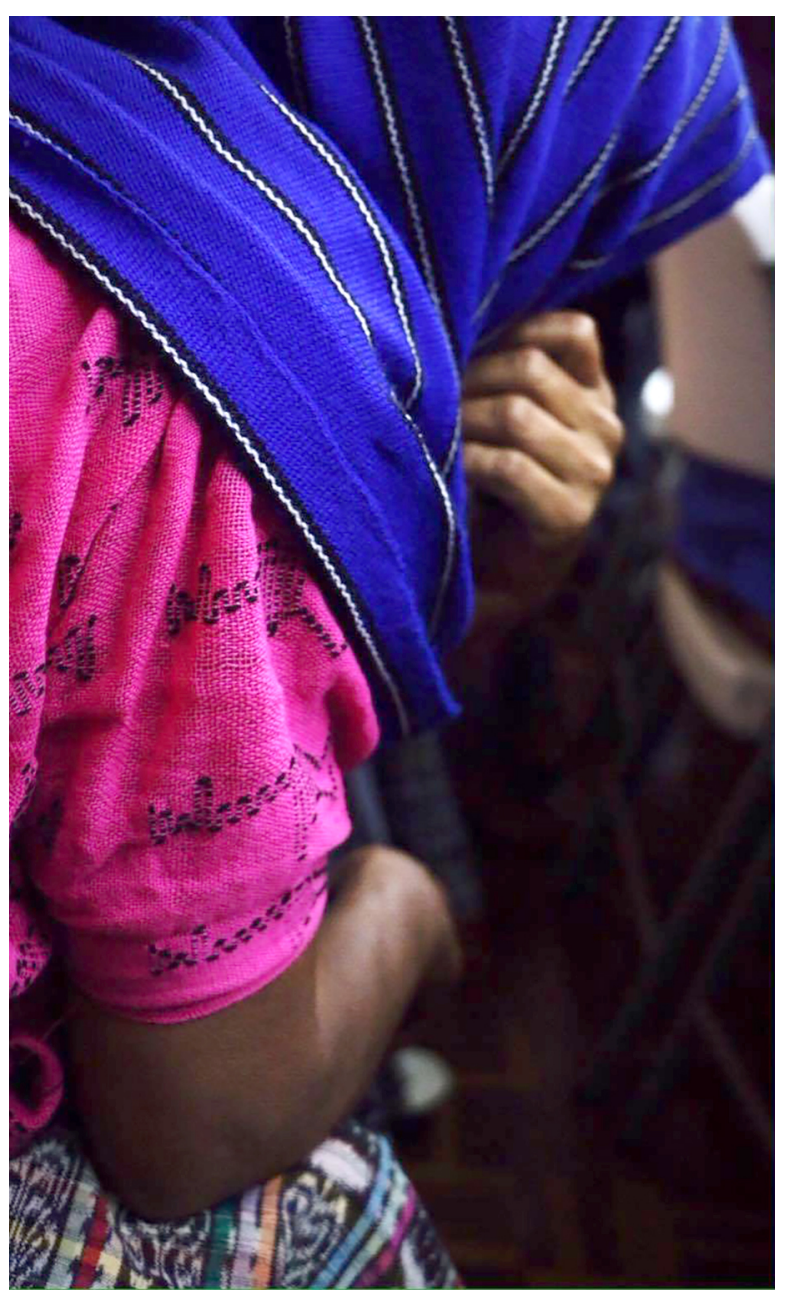

Fotografía por Andrea Carolina Estrada Rodríguez 
Artículos

\section{Referencias}

Didi-Huberman, G. (1990). Ante la imagen. Pregunta formulada a los fines de una historia del arte. Murcia, España: Editorial Centro de Documentación y Estudios Avanzados del Arte Contemporáneo CENDEAC.

Didi-Huberman, G. (2008). Cuando las imágenes toman posición. El ojo de la historia 1. España: Editorial Antonio Machado Libros.

La violencia sexual les marcó la vida-Zepur Zarco. (2016). Recuperado de https:// nuestramemorianuestraverdad.wordpress.com/2016/02/11/la-violencia-sexual-les-marco-la-vida-sepur-zarco/

Mitchell, W. J. T. (2009). Teoría de la Imagen. Ensayos sobre representación visual y verbal. España: Ediciones Akal.

Mitología en el arte. (2011). Rapto de Helena por Teseo y Piritoo. Recuperado de http://mitologiaenelarte.blogspot. com/2011/03/rapto-de-helena-por-teseo-y-piritoo.html

Museo de Arqueología de Cataluña. (s.f.). Mosaico del sacrificio de Ifigenia. Recuperado de http://visitmuseum. gencat.cat/es/museu-d-arqueologia-de-catalunya-empuries/objeto/ mosaic-del-sacrifici-d-ifigenia/

Romero, P. (s.f.). Metáfora de la imagen como mariposa. Entrevista realizada a Didi-Huberman.

Segato, R.L. (2014). Las nuevas formas de la guerra y el cuerpo de las mujeres. Sociedad e Estado,
29(2). Recuperado de http://dx.doi. org/10.1590/S0102-69922014000200003

Sontag, S. (2003). Ante el dolor de los demás. España: De Bolsillo.

Suárez-Toro, M. (2008). MUJERES metamorfosis del efecto mariposa. Colección Vitral. Costa Rica: Editorial Norma.

Tzul-Tzul, G. (2016). Voces que nos hace justicia a las mujeres. Guatemala: Centro de Estudios Mayas. Recuperado de http:// desinformemonos.org.mx/las-qeqchisde-sepur-zarco-voces-que-nos-hacejusticia-a-las-mujeres/

Wikimedia Commons. (2016). El rapto de Europa. Recuperado de https://commons. wikimedia.org/wiki/Francisco_de_Goya

Wikimedia Commons. (2016). Rape of Proserpine. Recuperado dehttps://commons. wikimedia.org/wiki/File:Abbate_-_Rape_ of_Proserpine_hi-res.jpg

Wikipedia. (2016). Mujeres de consuelo. Recuperado de https://es.wikipedia.org/ wiki/Mujeres_de_consuelo

Zambrano, M. (2012). La tumba de Antígona $y$ otros textos sobre el personaje trágico. España: Editorial Cátedra España. 